Counterfactual impact evaluation of EU funded enterprise support in Portugal

Ricardo Paes Mamede Teresa Fernandes Ana Alexandrino Silva

Dezembro de 2015 WP n. ${ }^{\circ} 2015 / 05$

DOCUMENTO DE TRABALHO WORKING PAPER 
Counterfactual impact evaluation of EU funded enterprise support in Portugal

Ricardo Paes Mamede * Teresa Fernandes $* *$

Ana Alexandrino Silva ***

WP n. 0 2015/05

DOI: 10.15847/dinamiacet-iul.wp.2015.05

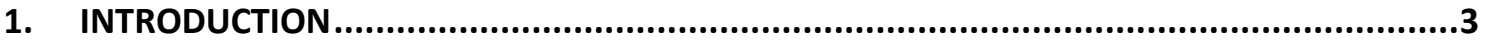

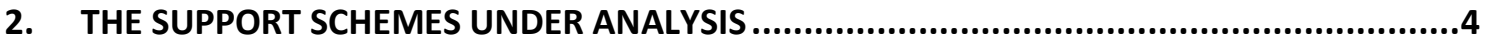

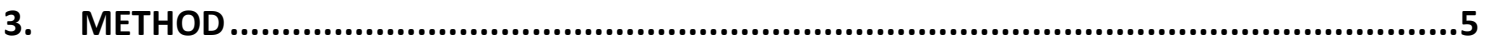

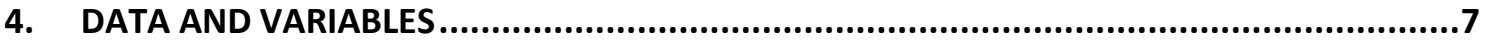

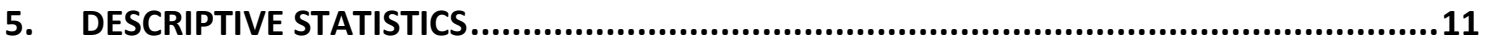

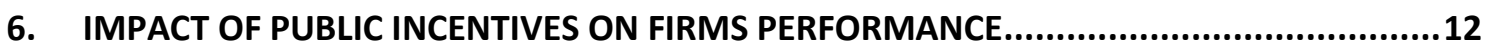

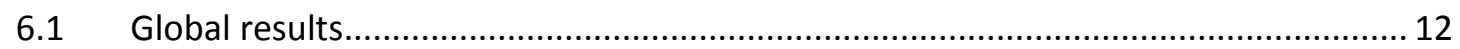

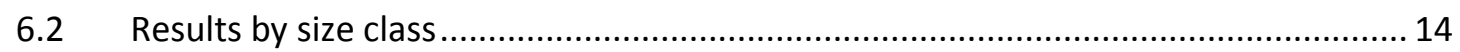

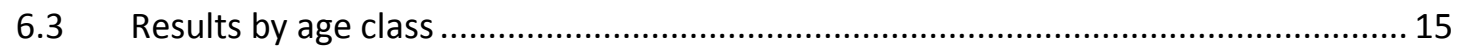

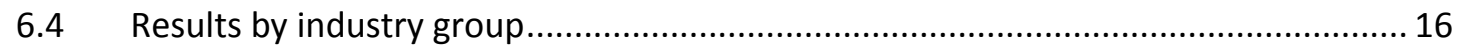

$6.5 \quad$ Results by intensity of skilled workers .................................................................... 17

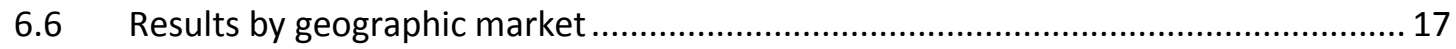

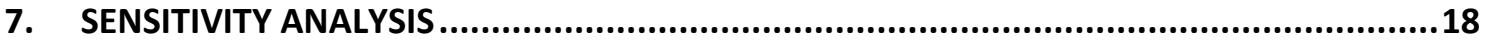

7.1 Robustness of the results with regard to the period under analysis ........................... 19

7.2 Robustness of the results when considering financial autonomy ............................. 20

7.3 Robustness of the results with regard to the aggregation method ............................. 22

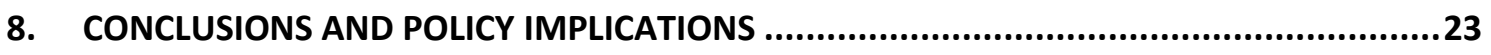

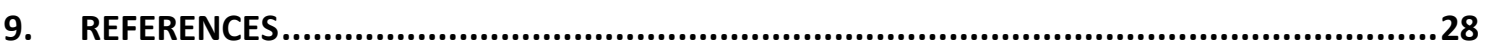

* DINÂMIA'CET - IUL and Instituto Universitário de Lisboa (ISCTE-IUL).

** DINÂMIA'CET - IUL and Instituto Universitário de Lisboa (ISCTE-IUL).

*** Agência para o Desenvolvimento e a Coesão. 


\title{
Counterfactual impact evaluation of EU funded enterprise support in Portugal ${ }^{1}$
}

\begin{abstract}
This paper uses a counterfactual approach to assess the impact of the main Operational Program of the EU Structural Funds in Portugal during the period 2000-2006 (POE/PRIME) on the performance of beneficiary firms. We find that public support to firms' investment increases their likelihood of survival after three years by 11 percentage points, and leads to the net creation of 2.1 additional jobs in the same period. The positive results obtained in our study suggest that the public support to firms' investment in Portugal in 2000-2006 was mostly well designed, at least in the light of the impact dimensions under analysis. The incentives were particularly effective in the case of firms that are typically more fragile (particularly, new firms and/or firms with low financial autonomy). We also find that the support had greater impacts in the case of large firms, and that the average cost per additional job created as a result of incentives was relatively modest.
\end{abstract}

\section{KEYWORDS}

Policy evaluation; Counterfactual impact evaluation; Enterprise support; EU Structural funds.

\footnotetext{
${ }^{1}$ This study benefited from the technical support of Daniel Bondonio, Professor at the University of Eastern Piedmont (Italy) and external expert of the European Commission. This paper benefited from comments on an earlier version by several Portuguese institutional partners. We are thankful, in particular, to the contributions of the technical staff of Observatório do QREN, COMPETE, CCDR Norte and IFDR. The responsibility for errors, omissions and conclusions presented herein, however, cannot be attributed to them. The authors would also like to thank the Office of Strategy and Planning of the Ministry of Solidarity and Social Security (GEP/MSSS), the Managing Authority of the COMPETE Operational Program and the National Institute of Statistics, who provided the data used in this study.
} 


\section{INTRODUCTION}

The EU Structural Funds are the most important source of funding for enterprise support mechanisms in Portugal. The need for a proper assessment of those mechanisms is widely recognized. The European Commission has been calling for a more rigorous and deep analysis of the impact of such policies, and urged Member States to adopt a counterfactual approach to the evaluation of public policies (e.g., EC, 2015).

Until recently, the evaluation of firm support schemes in most European countries has been based mainly on qualitative research methods and on the analysis of firm level indicators that are related with the underlying policy objectives (investment, job creation, innovation spending, etc.). In both cases, such approaches are essential for a proper monitoring of public policies: qualitative methods of evaluation are particularly useful in identifying the details of policy implementation, which are critical to public policies' success; and the analysis of indicators regarding the performance of supported firms can provide early signals that may lead to the timely introduction of adjustments on current interventions.

Notwithstanding, such methods do not capture accurately the effective impacts of public policies. In the case of qualitative methods, they do not allow for a rigorous quantification of the impacts, and their results are hardly generalizable. Regarding the analysis of the evolution of supported firms, this is typically insufficient to distinguish between performance traits that accrue from support schemes and those that are determined by other factors unrelated with the public policies under analysis.

The counterfactual approach that we apply in this study seeks to measure the impact of direct support schemes to firms' investment by comparing the performance of firms that received public support and the performance of similar firms that did not. This logic of analysis aims to isolate the effect of the public support on firms' performance from other factors.

The present analysis encompasses all enterprise support schemes managed by POE/PRIME, the main Operational Program of the EU Structural Funds in Portugal during the period 2000-2006 that had firms as direct beneficiaries. The policy instruments under analysis are largely similar to those in effect in the more recent programing periods, though they may differ from the latter in specific aspects. Furthermore, the economic context has changed dramatically between 2000-2006 and the following years. Therefore, the results obtained here may not be immediately generalized to enterprise support mechanisms that were more recently in place.

The data available at the firm level allowed us to include in the analysis a relevant set of variables characterizing the firms, as well as outcome variables which serve as a reference to 


\section{Counterfactual impact evaluation of EU funded enterprise support in Portugal}

estimate the impact of public policies. The information provided, and the methods used, allow us to produce new, reliable knowledge on the contribution of public support to the performance of Portuguese firms that benefit from such support.

This paper is organized as follows. Section 2 describes the enterprise support mechanisms under analysis. Section 3 briefly presents the method and the data used in the study. Section 3 provides a characterization of the total population of firms considered. Section 4 presents the estimated impacts of incentives in terms of firms' survival and net change in employment, with a special focus on the creation of skilled jobs. Section 5 is dedicated to the sensitivity analysis of those results. Finally, in Section 6 we summarize and discuss the main conclusions of the study, as well as the future developments of this work.

\section{THE SUPPORT SCHEMES UNDER ANALYSIS}

The policy interventions that have been subjected to the present counterfactual impact assessment include all the support schemes funded by the EU Cohesion Policy funds in the period 2000-2006 that (i) were managed by POE/PRIME² (the main Operational Program of the Third Community Support Framework in Portugal dealing with support to firms) and (ii) had firms as direct beneficiaries.

Even though POE/PRIME was not the only enterprise support program in Portugal during the period under analysis, it was by far the most relevant one both in terms of public funds and number of beneficiaries. Less than $1 \%$ of the firms that were supported under the schemes considered in the present study have received some kind of direct support from other programs. In this sense, we expect that the results of our analysis are not significantly affected by focusing solely on POE/PRIME direct support measures.

2 The Program was originally called POE (Operational Program for the Economy) and was lately renamed PRIME (Program for the Modernization of the Economy).

DINÂMIA'CET - IUL, Centro de Estudos sobre a Mudança Socioeconómica e o Território ISCTE-IUL - Av. das Forças Armadas, 1649-026 Lisboa, PORTUGAL

Tel. 210464031 - Extensão 293100 E-mail: dinamia@iscte.pt http://dinamiacet.iscte-iul.pt/ 


\section{METHOD}

The present study follows a counterfactual logic to estimate the impact of public incentives on the performance of firms. In other words, it seeks to answer the question: what would have happened if the public support had not existed?

In formal terms, let $\mathrm{T}_{\mathrm{i}} \in\{0,1\}$ denote a binary indicator for the treatment of firm $i$, with $\mathrm{T}_{\mathrm{i}}=0$ if a firm was not treated and $\mathrm{T}_{\mathrm{i}}=1$ corresponding to treatment. Let $\mathrm{y}_{\mathrm{i}}$ be the observable outcome for firm i. Then, the expected impact of public incentives can be represented as follows:

$$
\tau_{\mathrm{i}}=\mathrm{E}\left(\mathrm{y}_{\mathrm{i}}{ }^{1}-\mathrm{y}_{\mathrm{i}}^{0} \mid \mathrm{T}_{\mathrm{i}}=1\right)
$$

That is, the expected impact of the incentive on the treated firm corresponds to the difference between the expected value of the outcome variable in case of having been supported, $\mathrm{E}\left(\mathrm{y}_{\mathrm{i}}{ }^{1} \mid \mathrm{T}_{\mathrm{i}}=1\right)$, and the expected value of the outcome variable if the company had not benefit from public support, $\mathrm{E}\left(\mathrm{y}_{\mathrm{i}}^{0} \mid \mathrm{T}_{\mathrm{i}}=1\right)$.

Obviously, the direct estimation for the expected value of the performance in case the treated firm was not supported, $\mathrm{E}\left(\mathrm{y}_{\mathrm{i}}^{0} \mid \mathrm{T}_{\mathrm{i}}=1\right)$, is a logical impossibility. Aiming to overcome this fact, the impact evaluation methods using a counterfactual logic try to estimate, instead, the expected value of the performance for comparable non-treated firms.

In the specific case of direct support to firms, it is known that the performance of the beneficiaries depends on a wide range of factors beyond the public intervention, including their a priori characteristics. In fact, the determinants of firms' performance are not identically distributed across treated and non-treated firms. On the one hand, the decision to search and apply for public support is often related to characteristics that are also associated with firms' performance (e.g., management capacity, entrepreneurial drive). Moreover, the criteria used by public authorities for eligibility and assessment purposes (e.g., degree of innovation of the investment projects applying for support, the overall strategy of the firm, its degree of financial autonomy) may favour characteristics that are relevant to explain the future performance of firms, whether or not the firm obtains public support.

In other words, one could expect that the average performance of treated firms is distinct from the average performance of non-treated firms regardless of the real impact of incentives. As such, the simple comparison of firms' performance between the treated and nontreated ones reflects not only the performance differences accruing from public support, but also differences that result from a priori distinct features of firms. The purpose of counterfactual evaluation methods is, precisely, to estimate the impact of public policies by minimizing such 


\section{Counterfactual impact evaluation of EU funded enterprise support in Portugal}

selection effects. This is done by taking into account in the estimation of the policy impact those firm characteristics that are observable prior to the intervention. Formally:

$$
\tau(\mathrm{w})=\mathrm{E}\left(\mathrm{y}_{\mathrm{i}}{ }^{1}-\mathrm{y}_{\mathrm{i}}^{0} \mid \mathrm{T}_{\mathrm{i}}=1, \mathrm{X}_{\mathrm{i}}=\mathrm{x}_{\mathrm{i}}\right)
$$

The counterfactual analysis method used in this study is known in the literature as coarsened exact matching (e.g., Iacus et al., 2012). It consists on comparing the performance of groups of treated and non-treated firms that have substantively indistinguishable values for each variable. For that purpose, as a first step, treated and non-treated firms are segmented into groups based on the values of observable variables, which are coarsened in a customized way on the basis of substantive knowledge of the measurement scale of each variable. In a second step, we estimate the difference in the average performance of treated and non-treated firms within each stratum. Finally, we aggregate the results for the whole population of for specific types of firms by computing the weighted average of the impacts estimated for each stratum, with the weights being given by the number of treated firms in each stratum.

It is worth noting that in some cases coarsening is used in counterfactual evaluation only for the purposes of eliminating the differences between treated and control groups, which corresponds to the first step mentioned above. In those cases, coarsening is used as an alternative for other matching procedures (such as the more common propensity score matching), given its attractive properties (see Iacus et al., 2012) - especially when most of the control variables are categorical in nature, as in the present case ${ }^{3}$; after having eliminated the imbalances beyond the chosen level defined by the coarsening, the coarsened data are discarded and the original values of the matched firms are used at the analysis stage to estimate the impact of the intervention, typically using a regression framework.

In contrast, in the present study the coarsened data is also used in the estimation of the policy impact, by comparing the performance of treated and non-treated firms within each stratum. There are two main reasons behind this option. First, since all the relevant available data is used in the construction of our control variables, the method used here produces results that are similar to those resulting from a highly flexible multivariate regression approach to the estimation of policy impacts; in general terms, this method reduces the risks of model dependency, while efficiently controlling for selection bias. Secondly, our method allows for a direct comparison of the impacts of the policy for different categories of firms (more on this below), something which is unsatisfactory done on the basis of most regression analysis. Last

3 When most control variables are categorical, the propensity score method may not be the most appropriate one, since it does not guarantee that that treated firms are match with non-treated that are identical according to all variables - which can lead to significant selection bias. 


\section{Counterfactual impact evaluation of EU funded enterprise support in Portugal}

but not least, the method and the results of its application are easier to grasp by an audience not acquainted with more advanced statistical methods - as is typically the case of policy decision makers and civil servants responsible for the design and implementation of enterprise support mechanisms.

In addition to reducing the selection bias through coarsened exact matching, we use a specific method that allows for a direct comparison of the estimated impacts of the policies between categories of firms. In our study, this is done as follows. Suppose we want to compare the impact of the policy for new firms and for incumbent firms. For this purpose, and regarding the definition of a segment, which basically is a group of similar firms (the same age class, the same size class, and so on for all the remaining control variables used in the analysis), we will use only groups of comparable strata - each group is a set of strata that are similar in all the control variables, except for the one under analysis, in this case, age class.

So, first we estimate the impact for each stratum. Second, we compare the strata of new firms with the correspondent strata of incumbents, and keep the estimated impact differences between new firms and incumbents. Third, we compute the weighted average of those differences, separately for each category, using the proportion of treated firms in each stratum of that category (e.g., for new firms, we weight the impact differences between age classes by using the proportion of treated firms in each stratum of new firms $)^{4}$. The estimated impacts of the policy for new firms and for incumbents thus obtained are directly comparable, since they are purged of cross-effects. In other words, our method insures that differences between categories regarding the intensity of impacts are attributable only to the control variable under scrutiny.

\section{DATA AND VARIABLES}

This study uses the information available in official administrative records - namely, the Quadros de Pessoal database ${ }^{5}$ and the POE/PRIME database ${ }^{6}-$ in order to characterize firms according to a set of variables, and to analyze firms' performance in terms of survival, net change in employment, and net change in skilled employment. ${ }^{7}$

\footnotetext{
${ }^{4}$ If the number of categories in a control variable is higher than 2, each category segment will be compared with the weighted average of the other correspondent segments of the remaining categories in that control variable (weighted by the proportion of treated firms in each correspondent segment).

${ }^{5}$ This database contains information on all Portuguese firms employing at least one person, collected very year by the Portuguese Ministry of Employment on a compulsory basis.

${ }^{6}$ The information two databases were merged using a unique identification number, that correspond to a transformation of each firm's fiscal ID.

${ }^{7}$ Due to lack of data we are unable to assess the impact of firm support policies on performance variables such as sales, productivity, or profitability.
} 


\section{Counterfactual impact evaluation of EU funded enterprise support in Portugal}

The control variables were chosen on the basis of their influence on the performance of firms, which may be differently distributed between treated and non-treated firms. Based on the available information, we construct and use those control variables in order to compare the performance between treated and non-treated firms that have exactly the same values for each of those variables. This allows us to reduce the selection effects as well as to compare impact intensities between different types of firms, within each stratum.

The control variables used in this study are: size class, age class, geographic market, level of skilled employment, and sector of activity. The following table describes these variables and their operationalization, and discusses their relevance to the present analysis.

Table 1 - Control variables used in the analysis

\begin{tabular}{|c|c|c|}
\hline $\begin{array}{l}\text { Control } \\
\text { variable }\end{array}$ & categories & Description and justification \\
\hline Size class & $\begin{array}{l}\text { Micro (1 to } 9 \text { employers) } \\
\text { Small (10-49) } \\
\text { Medium (50 to } 249) \\
\text { Large ( } 250 \text { or more) }\end{array}$ & $\begin{array}{l}\text { Size tends to affect firms' performance in terms of growth and survival } \\
\text { (our outcome variables) (e.g., Geroski, 1995). }\end{array}$ \\
\hline Age class & $\begin{array}{l}\text { New firm (1-4 years old) } \\
\text { Established (5+ years old) }\end{array}$ & Age tends to affect firms' growth and survival (e.g., Geroski, 1995). \\
\hline $\begin{array}{l}\text { Industry } \\
\text { group }\end{array}$ & $\begin{array}{l}\text { High and medium-high } \\
\text { tech industries } \\
\text { Low and medium-low } \\
\text { tech industries } \\
\text { Construction } \\
\text { Tourism } \\
\text { Knowledge-intensive } \\
\text { services } \\
\text { Other services }\end{array}$ & $\begin{array}{l}\text { The type of industry may affect firms' growth and survival due to either } \\
\text { demand growth, competitive pressures, or technological opportunities } \\
\text { (e.g., Bernard and Jones, 1996; Dosi, 1982). We follow the } \\
\text { classification of industries by technology and knowledge intensity used } \\
\text { by Eurostat, and adapt it in order to isolate the tourism sector (using the } \\
\text { classification by the Portuguese National Statistics Institute), given its } \\
\text { specificities and prominent role in the Portuguese economy. }\end{array}$ \\
\hline $\begin{array}{l}\text { Level of } \\
\text { skilled } \\
\text { employment }\end{array}$ & $\begin{array}{l}\text { High-intensity } \\
\text { on skilled employment } \\
\text { Low-intensity } \\
\text { on skilled employment }\end{array}$ & $\begin{array}{l}\text { It is a proxy for the sophistication of production and management at the } \\
\text { firm level, assuming that this may affect firms' performance (e.g., } \\
\text { Boxall \& Macky, 2009). A firm is considered as having a high intensity } \\
\text { of skilled employment if the share of skilled workers in that firm is } \\
\text { higher than the one observed for firms of the same size class and } \\
\text { industry ( } 3 \text { digits NACE Rev.1.1). }\end{array}$ \\
\hline $\begin{array}{l}\text { Geographical } \\
\text { market }\end{array}$ & $\begin{array}{l}\text { Suprarregional } \\
\text { Infrarregional Norte } \\
\text { Infrarregional Centro } \\
\text { Infrarregional Lisboa } \\
\text { Infrarregional Alentejo } \\
\text { Infrarregional Algarve } \\
\text { Infrarregional Madeira } \\
\text { Infrarregional Açores } \\
\end{array}$ & $\begin{array}{l}\text { We assume that firm's performance is also affected by the evolution of } \\
\text { the relevant geographical market in which a firm operates. In order to } \\
\text { define the relevant market we take into consideration both the size and } \\
\text { the industry ( } 5 \text { digit NACE rev.1.1) classifications: all firms with } 50 \text { or } \\
\text { more employees are assumed to operate in supra regional markets; the } \\
\text { same applies to manufacturing knowledge-intensive services firms with } \\
10 \text { to } 49 \text { employees; the remaining firms are considered to have as their } \\
\text { relevant market the region (NUTS II) where they are located. }\end{array}$ \\
\hline
\end{tabular}

Additionally to the characterization of treated and non-treated firms, our database includes information on the incentives granted to the beneficiaries of POE/PRIME support mechanisms. For each firm, we identify the last year in which the firms received support, the total amount of public funds granted, and the corresponding support mechanism. For the present purpose, we consider the last year of support, $\mathrm{T}$, as the moment from which the public support begins to produce effects. 


\section{Counterfactual impact evaluation of EU funded enterprise support in Portugal}

In order to assess the impact of public policies we compare the performance of treated and nontreated firms that had similar characteristics before public support started to produce effects. More specifically, we consider the characteristics (i.e., the values of control variables) of treated firms at T-1 and compare their performance with that of the non-treated firms that existed in the year T-1 and had exactly the same characteristics in that same year. ${ }^{8}$

For assessing the impact of public support on firms' survival, we estimate the difference between groups of treated and non-treated firms regarding the proportion of firms that were active between $\mathrm{T}-1$ and $\mathrm{T}+2$, for each stratum of firms with similar characteristics (i.e., firms with the same values in the control variables in T-1).

In the analysis of the impact of support on net change in employment, we estimate the difference between groups of treated and non-treated firms regarding the average net change in employment between $\mathrm{T}-1$ and $\mathrm{T}+2$, for each stratum of firms with similar characteristics (i.e., firms with the same values in the control variables in T-1). Note that for this output variable we only consider firms that were still active at $\mathrm{T}+2$. In other words, we do not consider the employment evolution of firms that are no longer active. Assuming that survival is in itself a reflection of firms' characteristics that may not be captured by the control variables used in the study, this option allows us to further reduce the selection effects on the estimation of the impact of public support.

In both cases, the estimated aggregate impact of public policy for a set of firms is the weighted average of the estimated impacts for each stratum, with weights being given by the proportion of treated firms in that segment.

A common issue concerning this type of analysis is the fact that some firms benefit from support for more than one project, making it difficult to identify the moment at which the support begins to take effect. For this reason, we chose to consider only those firms that received support only once under the POE/PRIME.

In addition, we also excluded from the analysis firms that do not meet one or more of the following conditions:

- To be recorded in the administrative database in between 2000 and 2006 (our T variable) and having been supported within this period (only for treated firms);

- To have no gaps in the records;

- To have no public or foreign capital (on the grounds that, in these cases, the performance of firms tends to be more often associated with factors that are not captured by the variables available for analysis);

\footnotetext{
${ }^{8}$ By having the same reference year for both treated and non-treated firms we are also controlling for the influence of the macroeconomic context on the performance of firms.
}

DINÂMIA'CET - IUL, Centro de Estudos sobre a Mudança Socioeconómica e o Território ISCTE-IUL - Av. das Forças Armadas, 1649-026 Lisboa, PORTUGAL

Tel. 210464031 - Extensão 293100 E-mail: dinamia@iscte.pt http://dinamiacet.iscte-iul.pt/ 


\section{Counterfactual impact evaluation of EU funded enterprise support in Portugal}

- To have the legal status of limited liability companies, limited companies, or sole proprietors (with at least one employee);

- To be classified as a market-oriented industry (excluding, therefore, personal and collective services), excluding temporary employment services (given the atypical annual variations in the volume of workers in this industry);

- To have no more than 100 workers in the entry year (as to dismiss 'new' firms resulting from mergers, acquisition, changes of legal status, etc.);

- In the case of treated firms (for which data from different sources was crossed), to have consistent information between different databases used in the study.

After constructing the strata of firms, on the basis of the variables listed in Table 1, we also excluded treated (non-treated) firms that had no corresponding non-treated (treated) units.

Figures 1 and 2 show the number of firms (total and treated) excluded from the analysis as a result of the application of the criteria above ${ }^{9}$. Among these, the criteria that led to a larger number of excluded firms that were supported for the last time within 2000 and 2006 were gaps in administrative records and inconsistency between different databases (only for treated firms).

Figure 1: Excluded firms (treated and nontreated) by exclusion criteria

\begin{tabular}{r|l} 
Gaps between QP records & 133898 \\
Only one employer recorded & \\
\cline { 2 - 2 } Segment without treated or non-treated & \multicolumn{2}{|c}{49568} \\
Non-market oriented legal nature & 45774 \\
Non-market oriented NACE & 12656 \\
Firm with public capital & 8464 \\
Firm with foreign capital & 1429 \\
Inconsistent data - PRIME vs QP & 1115 \\
Temporary employment services & 815 \\
Outliers - net employment growth & 649 \\
New large firms (above 100 workers) & 460 \\
POE/PRIME programmes excluded & 73 \\
Outliers - large firms & 5 \\
Treated outside the 00-06 period & 0
\end{tabular}

- Firms within the $95-09$ period
Figure 2: Excluded treated firms by exclusion criteria

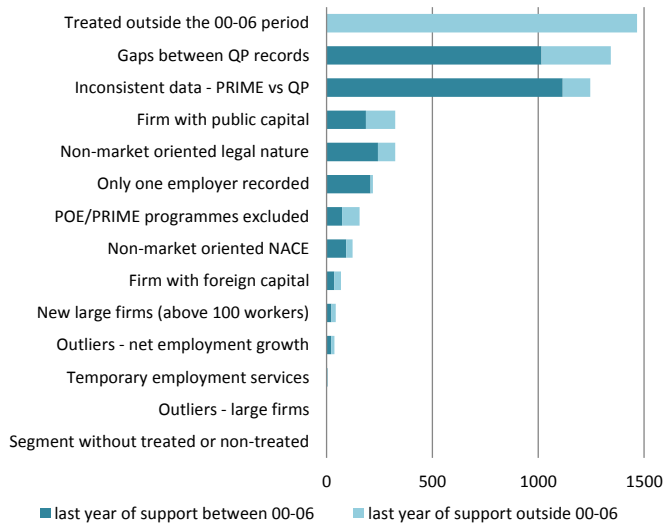

${ }^{9}$ The exclusion of one firm may result from more than one criterion. 


\section{Counterfactual impact evaluation of EU funded enterprise support in Portugal}

\section{DESCRIPTIVE STATISTICS}

After the data cleaning process previously described, 3.904 treated firms and 221.258 nontreated ones were kept for analysis. The treated firms considered in the study represent $59 \%$ of total POE/PRIME beneficiaries in the period of 2000-2006 and 48\% of firms that were supported throughout the program (which lasted up to 2009). Figures 3 to 8 show the composition of the sample according to the control variables discussed in the previous section.

Figure 3: Total of treated and non-treated firms

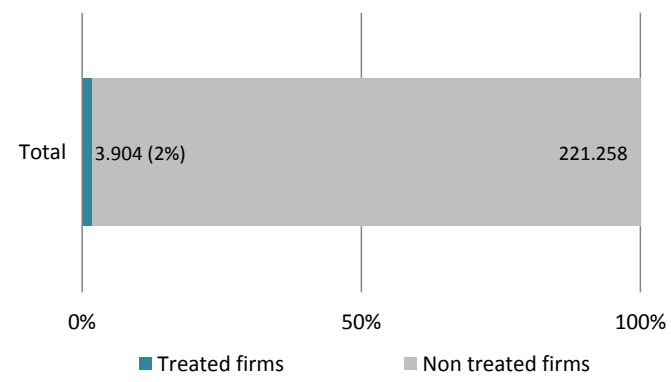

Figure 5: Treated and non-treated firms by age class firms

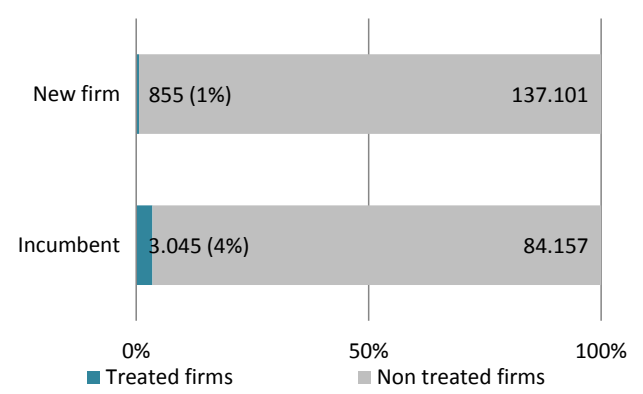

Figure 7: Treated and non-treated firms by degree of intensity on skilled employment

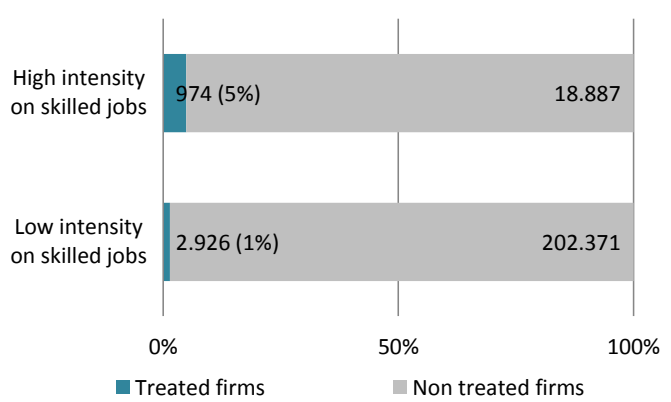

Figure 4: Treated and non-treated firms by size class

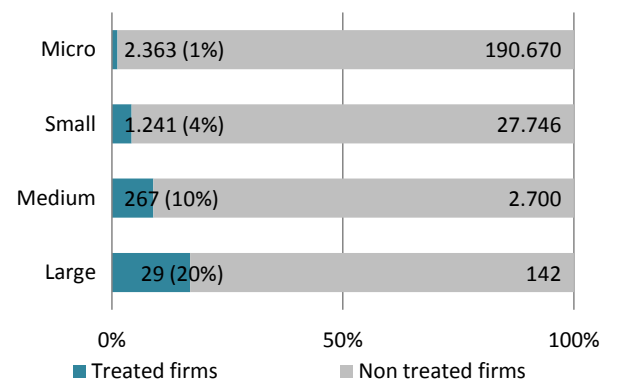

Figure 6: Treated and non-treated firms by type of industry

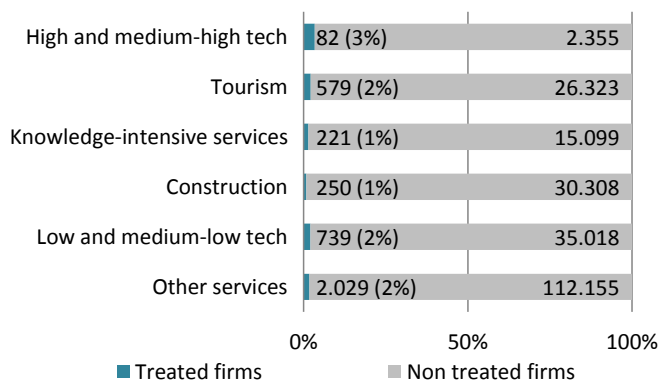

Figure 8: Treated and non-treated firms geographical scope of the business

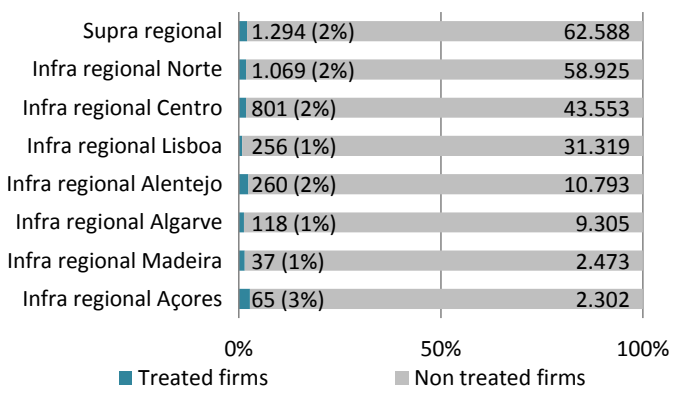


As can be seen in these figures, the proportion of treated firms is always less than 5\%, with the exception of medium and large firms (among which treated firms represent $10 \%$ and $20 \%$ of the total number of firms, respectively).

\section{IMPACT OF PUBLIC INCENTIVES ON FIRMS PERFORMANCE}

This paper estimates the impact of incentives to firms according to three outcome variables: (i) survival rate; (ii) net employment growth; and (iii) net skilled employment growth.

Additionally, we also estimate the average cost per job resulting from public support, corresponding to the ratio between the amount of support and the estimated impact on net employment. ${ }^{10}$

In what follows we present not only the overall results obtained for these four variables, but also the comparison of impacts among categories of firms, within each control variable (size class, age class, geographic market, level of skilled employment, sector of activity). In other words, we analyse to what extent the impacts of the incentives are different for distinct categories of firms.

\subsection{Global results}

According to our results, the incentives granted to firms between 2000 and 2006 by POE/PRIME had a positive and statistically significant impact in all three performance variables use in our study: survival, net change in employment, and net change in skilled employment. $^{11}$

With regard to survival, the proportion of treated firms remaining active after three years is $96 \%$, compared to a survival rate of $85 \%$ for comparable non-treated firms. Thus, it can be stated that public incentives increased by 11 percentage points (p.p.) the probability of survival of treated firms.

Considering the employment evolution of surviving firms, the estimated results show that, after three years, each treated firm created 1,4 jobs (average net jobs), while each non-

\footnotetext{
${ }^{10}$ Note that the total amount of support does not necessarily correspond to the effective support granted to firms, since at least part of the incentive consist of a soft loan, rather than a grant. Unfortunately, the data we use in this study those not allow us to differentiate the two types of support, nor to work with a comparable measure (such as the gross grant equivalent). Accordingly, our estimates of average costs for support should be taken the maximum amount of support per net job created.

${ }^{11}$ The corresponding standard deviations and t-statistics are as follows:

- $\quad$ Survival sd(0.01) t-stat(19.80)

New jobs sd(0.06) t-stat(33.57)

New HighEd jobs sd(0.03) t-stat(5.72)

DINÂMIA'CET - IUL, Centro de Estudos sobre a Mudança Socioeconómica e o Território ISCTE-IUL - Av. das Forças Armadas, 1649-026 Lisboa, PORTUGAL

Tel. 210464031 - Extensão 293100 E-mail: dinamia@iscte.pt http://dinamiacet.iscte-iul.pt/
} 
treated firm lost 0,7 jobs. Thus, it is estimated that public incentives led, on average, to the net creation of more 2,1 jobs in a treated firm than in a comparable non-treated one. And, in particular, of more 0,2 jobs when considering only skilled employment.

Finally, we estimate that, each net job resulting from the public support to firms required, at most, 55 thousand euro of public funds.

Figure 9: Comparing firms' performance between treated and non treated firms (after three years)
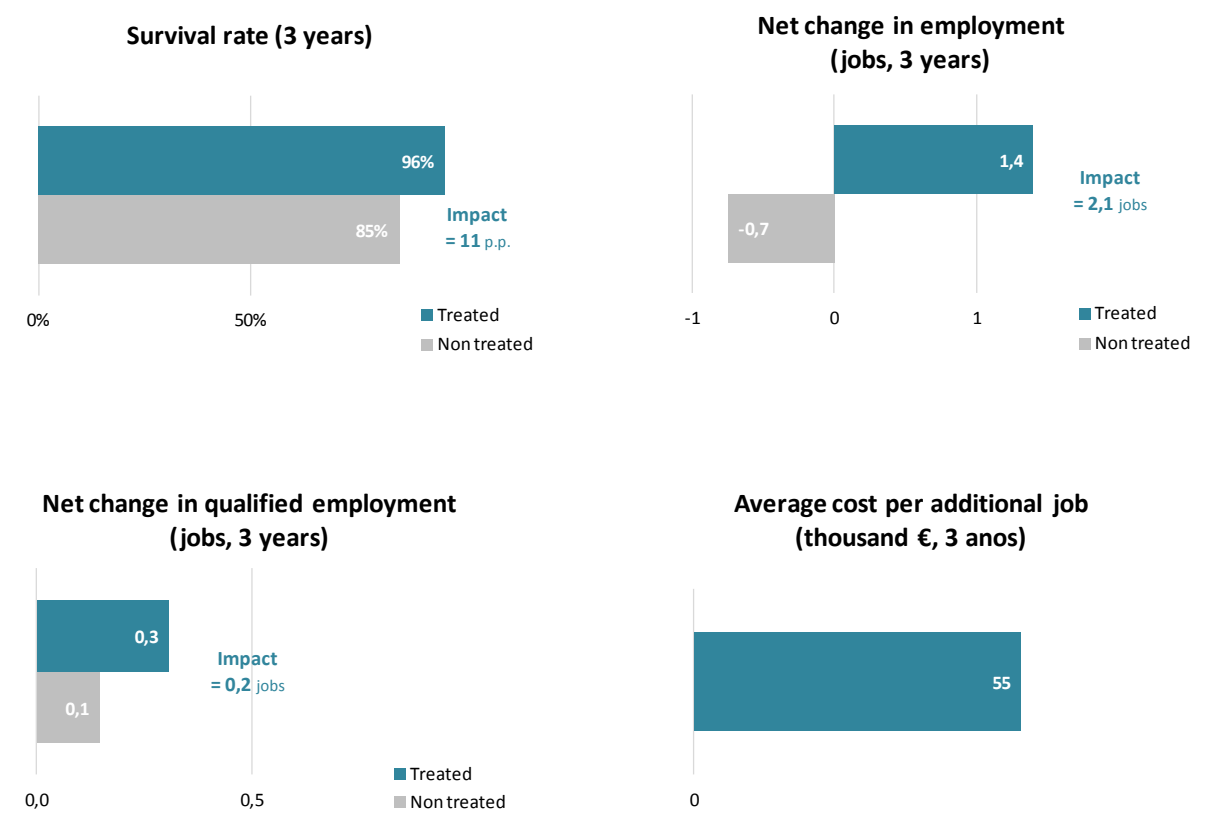

The estimated impacts are positive for the whole set of firms under analysis, as well as for each single category of firms considered in this study. In the following sections we present the impact of incentives in each category (e.g., small firms) in comparison with the impact on firms that share the same characteristics except for the variable under consideration (e.g., all except class size). 


\subsection{Results by size class}

Regarding survival, the impact of public incentives is more pronounced in the case of microfirms - the contribution of incentives for survival in this case is five percentage points above the impact on survival for the other size classes. In contrast, the impact of incentives on the survival of large firms is substantially lower than that estimated for the comparable non-large firms.

As for net job creation, the impact of public support is substantially higher in the case of large firms, in comparison with similar firms in other size classes. And although the average amount of support is higher for large firms, still the average cost per job created in large firms is less than that of other size classes.

The impact in terms of skilled labor is more relevant in the case of small and medium firms.

Figure 10: Comparing impacts between size classes (after three years)

Comparing the impact on survival (p.p., 3 years)

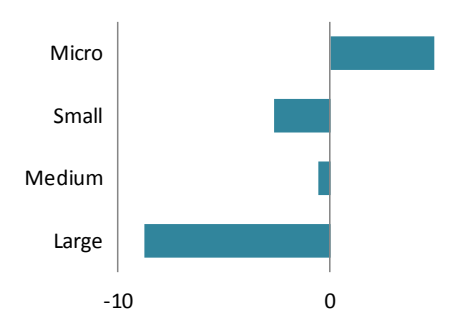

Comparing the impact on skilled employment (qualified jobs, 3 years)

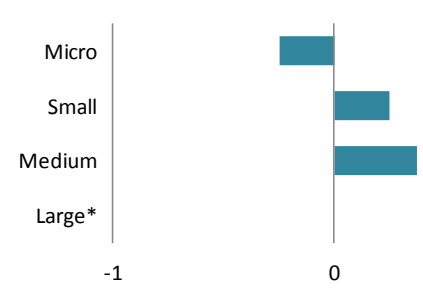

Comparing the impact on employment (jobs, 3 years)

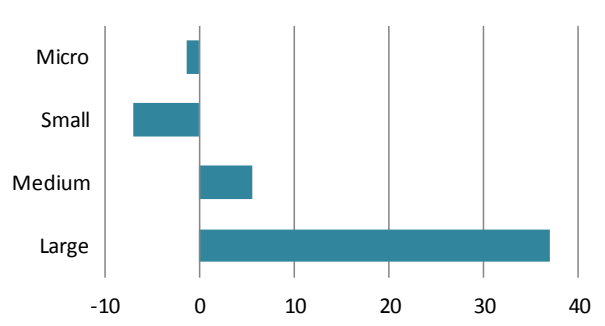

Comparing the average cost per additional job (thousand $€, 3$ years)

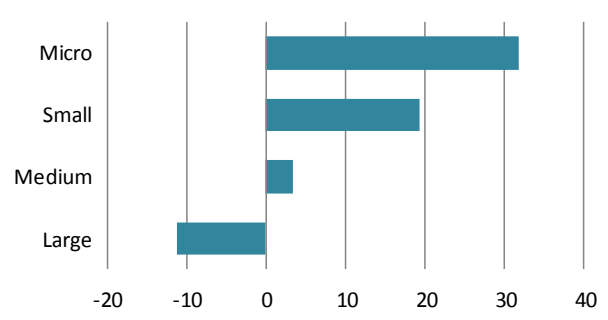

* The estimated difference is not statistically significant. 


\subsection{Results by age class}

Regardless of the size class (and other characteristics considered in the analysis), the impact of public incentives on firms performance - both in terms of survival, total employment or skilled employment - is greater in the case of newer firms than in incumbent firms.

Conversely, the average cost per job created is higher in the case of incumbent firms than in younger firms.

Figure 11: Comparing impacts between age classes (after three years)

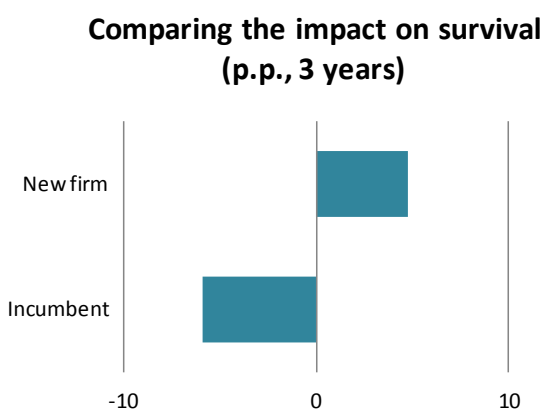

Comparing the impact on skilled employment (qualified jobs, 3 years)

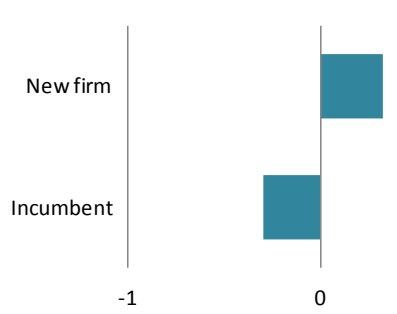

Comparing the impact on employment (jobs, 3 years)

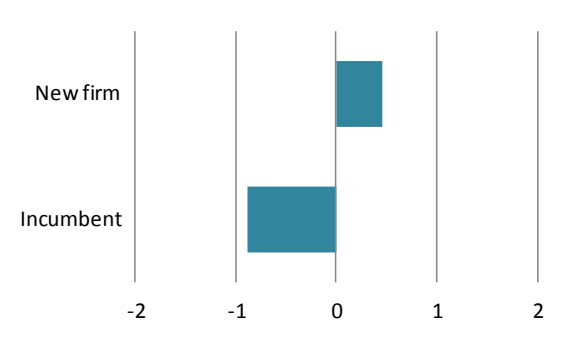

Comparing the average cost per additional job (thousand $€, 3$ years)

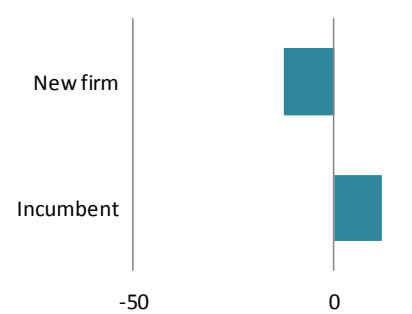




\subsection{Results by industry group}

The positive impact of public incentives on firms' survival is more pronounced in the case of low and medium-low tech industries and in construction, and is less significant in industries with a higher intensity of knowledge or technology (either in manufacturing or in services)

Regarding the impact on net change of employment, the positive effects are higher in construction firms, which also show a smaller average cost per additional job, unlike the tourism sectors.

Regarding skilled employment, low and medium-low technology industries display a higher impact, in contrast with the high and medium-high tech industries.

Figure 12: Comparison impacts between sectors of activity (after three years)

Comparing the impact on survival

(p.p., 3 years)

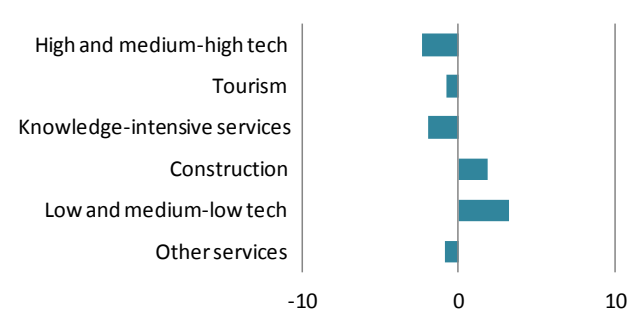

Comparing the impact on skilled employment (qualified jobs, 3 years)

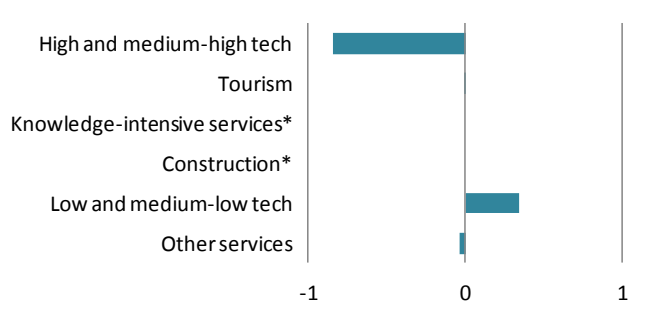

Comparing the impact on employment (jobs, 3 years)

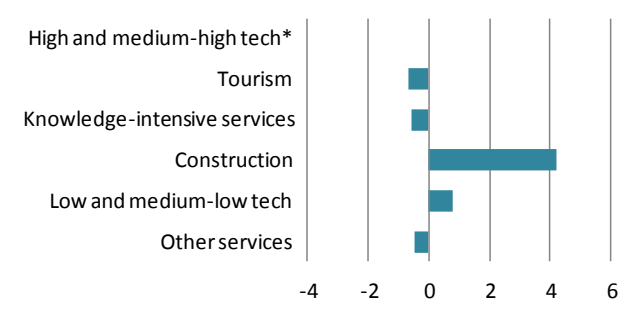

Comparing the average cost per additional job (thousand $€, 3$ years)

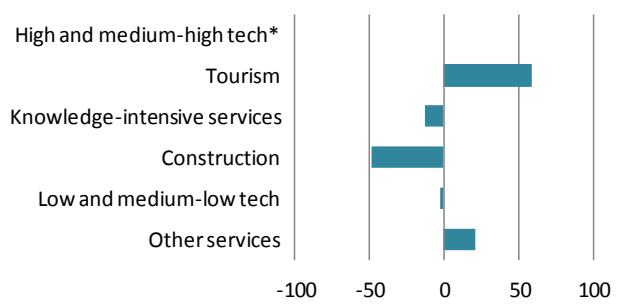

* The estimated difference is not statistically significant 


\subsection{Results by intensity of skilled workers}

Regardless of the structural characteristics of firms (size class, age class and division) and the other characteristics considered, the impact of incentives both in terms of survival and total employment is more pronounced in the case of firms with a lower proportion of under-graduates in their work force. The opposite applies for the average cost per job created as a result of public support, which is higher for firms that are more intensive in skilled labour.

As regards the net change on skilled employment, the impact of support is slightly more pronounced in the case of firms with greater intensity of skilled employment.

Figure 13: Comparing impacts between levels of skilled employment (after three years)

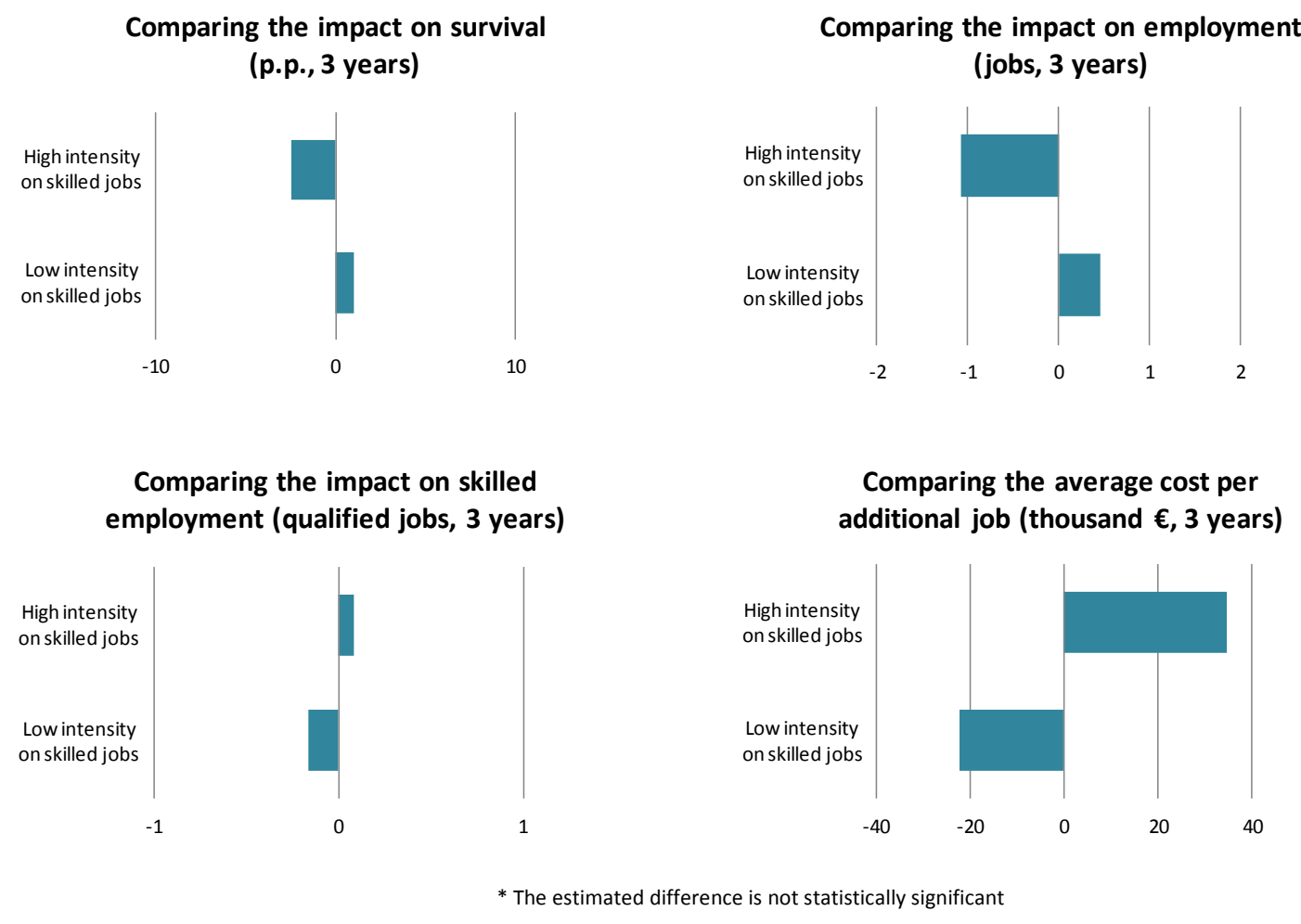

\subsection{Results by geographic market}

The impact on survival for firms operating mainly in infra-regional markets is more pronounced then the impact estimated for similar firms that operate in supra-regional markets. Conversely, the impact on net job creation is higher for firms operating in supra-regional markets, and their average cost per job created is lower. 


\section{Counterfactual impact evaluation of EU funded enterprise support in Portugal}

The differences between the two types of firms as regards the creation of qualified jobs are of little relevance.

Figure 14: Comparing impacts between geographical markets (after three years)

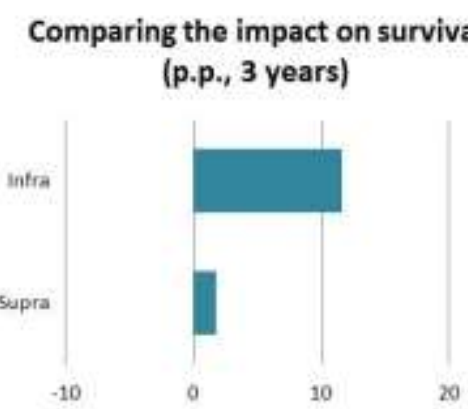

Comparing the impact on skilled employment (qualified jobs, 3 years)

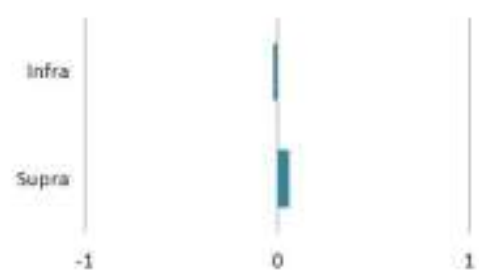

Comparing the impact on employment (jobs, 3 years)

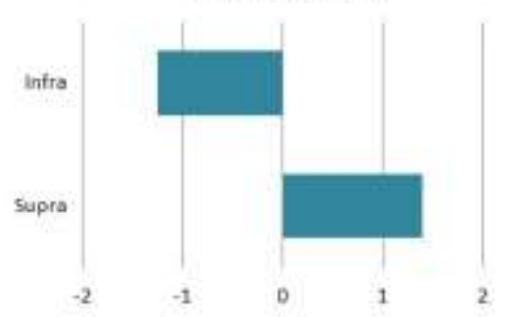

Comparing the average cost per additional job (thousand $\mathbf{\epsilon}, 3$ years)

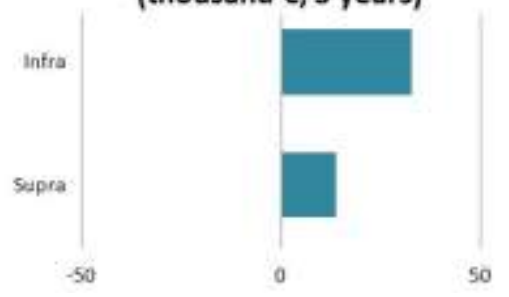

\section{SENSITIVITY ANALYSIS}

The results presented above were obtained on the basis of available and relevant information from the Quadros de Pessoal database and from POE/PRIME database, between 1999 and 2008, using specific methods for the impact estimation and results aggregation.

Each step in this process implied methodological choices that are justifiable in light of the information available and the purposes of the study. Of course, these options are not unique and may lead to results that are not validated when using other methodological choices. In this section we present and discuss the robustness of the results presented before by analysing their sensitivity to different methodological choices.

One of the weaknesses of the analysis above may be the failure to consider the degree of firms' financial autonomy. Typically, the firms' access to an incentive is subjected to compliance with certain minimum levels of its financial autonomy ${ }^{12}$. The existence of such a

\footnotetext{
12 This is in order to reduce the risk of non-execution of the approved project, due to the fragility of a firm's balance sheet.
} 


\section{Counterfactual impact evaluation of EU funded enterprise support in Portugal}

constraint implies that the distribution of the ratio of financial autonomy is not identical between treated and non-treated firms. More specifically, the average levels of financial autonomy tend to be higher for the treated firms. Since the levels of financial autonomy tend to affect the performance of a firm ${ }^{13}$ regardless of public incentives, failing to consider this selection effect may prevent the correct identification of the changes in performance that are attributable to the support.

Using micro data provided by the National Statistics Institute, it was possible to add the degree of financial autonomy (i.e., the ratio of Equity to Total Assets) to the set of control variables, as a way to reduce the aforementioned selection effect. Unfortunately, such information is available from 2004 onwards. Thereby, it can only be considered in the analysis for the specific period of 2005-2006, and we use it as a sensitivity test of the main results (considering only the data for that specific period). We also use the data provided by INE to compare the impacts of public support across different categories of firms according to their degree of financial autonomy.

Since, for the sake of comparability, this sensibility analysis required us to re-estimate the impacts presented in Section 4 considering only the period 2005-2006, we use such new results as an additional sensibility test. This comparison allows us to test whether the results vary considerably when different time periods are under consideration.

Finally, we briefly discuss the robustness of the obtained results with regard to alternative methods of weighing across strata of firms.

\subsection{Robustness of the results with regard to the period under analysis}

We re-estimated the impacts of support on firm's performance, but now considering only the period 2005-2006 (instead of 2000-2006), and including only the firms that were registered in both Quadros de Pessoal and INE databases. The results demonstrate the robustness of the findings presented in Section 4, confirming both the direction and the intensity of the estimated impacts (the only difference worth noticing is the slightly more pronounced impact on job creation in the period 2005-2006).

\footnotetext{
${ }^{13}$ To the extent that it influences the ability to mobilize resources and access bank credit. 


\section{Counterfactual impact evaluation of EU funded enterprise support in Portugal}

Figure 15: Comparing impacts between periods of analysis (after three years)

Impact on survival (3 years)

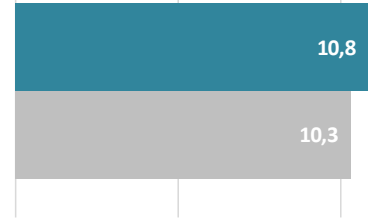

10

Impact on skilled employment ( 3 years)

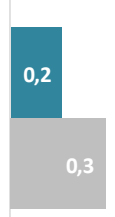

0
$2000-2006$

$2005-2006$

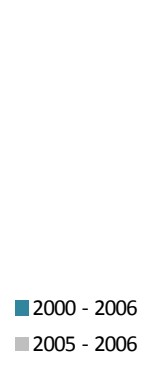

$2000-2006$

$2005-2006$
Impact on employment ( 3 years)

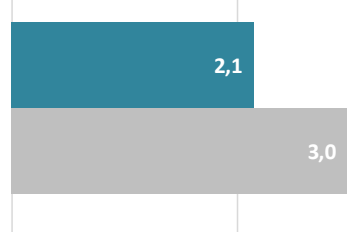

0

2

2000 - 2006

- $2005-2006$

The same applies for the comparison of the impacts among different categories of firms between 2000-2006 and 2005-2006 (the differences between categories are slightly more pronounced for the period of 2005-2006, mainly for the size class and geographical market variables).

\subsection{Robustness of the results when considering financial autonomy}

Next, we compare the results obtained using our two main databases (Quadros de Pessoal and POE/PRIME's) with the ones that are obtained when the degree of financial autonomy is added to the control variables (only for the period 2005 to 2006). The difference between the estimated impacts in the two analyses are practically inexistent, both in terms of direction and intensity of the impacts. 
Counterfactual impact evaluation of EU funded enterprise support in Portugal

Figure 16: Comparing impacts between control structures (after three years)

Impact on survival (3 years)

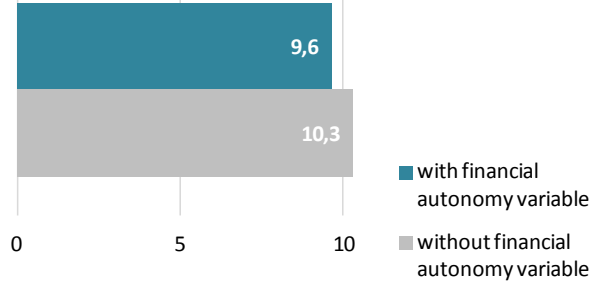

Impact on skilled employment ( 3 years)

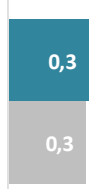

0 with financial

autonomy variable

without financial

autonomy variable
Impact on employment (3 years)

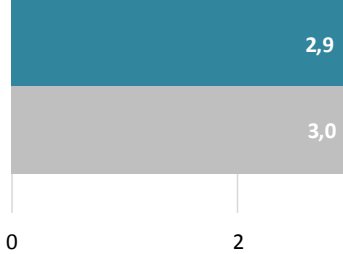

with financial

autonomy variable

without financial

autonomy variable

Average cost per additional job (thousand $€, \mathbf{3}$ years)

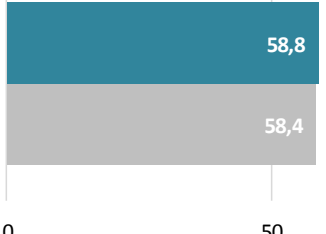

with financial autonomy variable

without financial autonomy variable

Regarding the analysis of the partial impacts, the results obtained for this two control structures (with and without the degree of financial autonomy), coincide in most cases, both in the direction and in the intensity of the impact. The only remarkable differences, when considering the degree of financial autonomy as a control variable, concerns the category of low intensity in skilled employment, for which the estimated impact is smaller for the net change in employment and higher for the average cost per additional job.

In addition to the sensitivity analysis, the data on financial autonomy allows to compare the impact between firms displaying different values for this variable. We conclude that the positive impacts are higher for the lowest degree of financial autonomy (in terms of survival, net change in employment and net change in skilled employment), although they require greater amounts of support per additional job. 


\section{Counterfactual impact evaluation of EU funded enterprise support in Portugal}

Figure 17: Comparing impacts between degrees of financial autonomy (after three years)

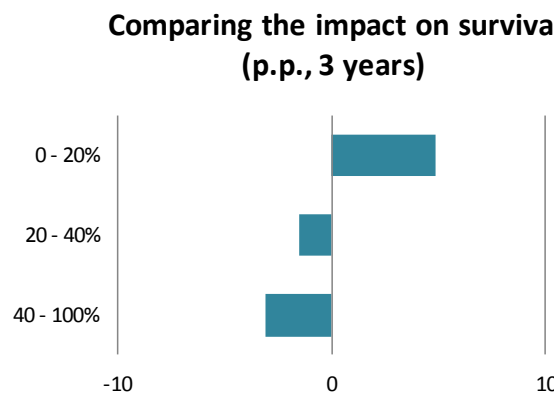

Comparing the impact on skilled employment (qualified jobs, 3 years)
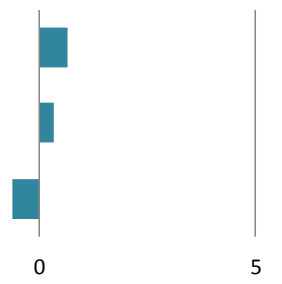
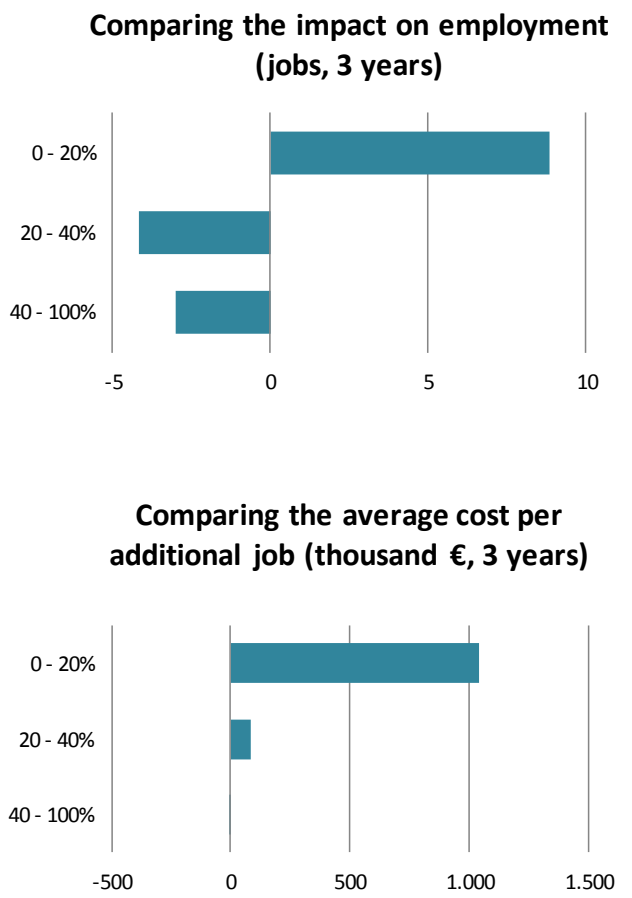

\subsection{Robustness of the results with regard to the aggregation method}

When comparing the impacts for different firm categories (e.g., micro firms with the remaining size classes), it is necessary to bear in mind that different categories have asymmetric distributions with respect to the other firms' characteristics considered for building the strata (following the previous example: age, sector, geographical market and intensity in skilled employment). The estimation method should ensure that these compositional differences do not influence the results.

The method we used above to aggregate the impacts by category considers the composition of firms' characteristics of each category, in order to estimate both the aggregated impact for that category and the aggregated impact for the other categories. Doing so, the composition of firms' characteristics of a given category does not affect the comparison between categories.

To ensure the robustness of the main results obtained, we repeat the exercise of comparing the impacts of incentives between categories, but considering instead the composition of firms' characteristic for the whole set of firms under analysis.

The results confirm, in general, both the direction and the size of the differences between categories. 


\section{Counterfactual impact evaluation of EU funded enterprise support in Portugal}

\section{CONCLUSIONS AND POLICY IMPLICATIONS}

The main results of this study can be summarized as follows. With reference to the whole set of supported firms, we conclude that:

- Public support to firms' investment increases their likelihood of survival (three years after the end of the support) by 11 p.p..

- Among surviving firms, support leads to the net creation of 2.1 additional jobs and 0.7 additional qualified jobs per firm (at the end of three years).

- On average, for each 55 thousand euros of public support to firms, one additional net job was created.

Comparing the impacts of incentives between categories of firms, we conclude that ${ }^{14}$ :

- The impact of support on survival is more pronounced for firms with fewer than 10 employees, new firms, firms from low and medium-low technology industries, firms operating in regional markets, and firms with lower levels of financial autonomy. By contrast, although positive, the impact is less relevant for large firms, incumbent firms (four or more years old), firms with high intensity of skilled labour, and firms in high knowledge and technology intensive industries (both in manufacturing and in services).

- The impact of incentives on net change in employment is more significant for large firms, firms that operate in supra-regional markets (regardless of the size class), construction firms, new firms, and firms with lower levels of financial autonomy. Conversely, the public support under consideration induced a positive, though less expressive, net change in employment in the case of incumbent firms and firms with above-average intensity of skilled labour.

- The impact of incentives on the net change of skilled employment is more pronounced in the case of small and medium firms, new firms, firms targeting a supra-regional market, firms that are intensive in skilled workers, and firms with lower levels of financial autonomy. Conversely, the public support under consideration induced a net change in skilled employment less pronounced in the case of micro firms, incumbent firms, firms with low intensity of skilled labour, and in high and medium-high technology industries.

- The average cost per additional job, is smaller for large firms, new firms, firms targeting an infra-regional market, construction firms, and firms with a ratio of skilled workers below average. Conversely, the amount of incentive per additional job is higher in the tourism industry, in firms with fewer than 50 employees, in incumbent firms, and in firms with high-intensity of skilled labour.

\footnotetext{
${ }^{14}$ Recall that the results are free from cross-effects between the variables. 
- Finally, the impact of incentives on survival and employment is inversely proportional to the degree of financial autonomy of firms. However, the average cost per additional job is greater in the case of firms with reduced financial autonomy.

The results obtained in this study give rise to a set of considerations that are relevant to the design and implementation of this type of policies. They are discussed below in greater detail.

1) The positive results obtained in our study suggest that the public support to firms' investment in Portugal in 2000-2006 was mostly well designed, at least in the light of the impact dimensions under analysis.

According to our results, the impact of public support is positive in light of the three outcome variables under analysis (survival, employment, and skilled labour), for all categories of firms, in spite of differences in the intensity of the impact across categories. This leads us to conclude that the design and implementation of incentives POE / PRIME, within the framework of State aid rules in force, were broadly appropriate.

It should be noted, however, that the main objectives underlying these policy instruments does not correspond directly to the outcome variables that were considered in this study. Although it is desirable that these schemes increase the probability of survival of supported firms and induce net job creation, the fact that they do so does not directly mean that the policies in question have reached their goals, which are associated with more specific targets such as enhancing productivity, innovation and internationalization, and changing the specialization profile of Portuguese economy. Furthermore, in some cases, it is not possible to exclude that the incentive systems may be encouraging job growth and firms' survival without entailing substantial contributions to the achievement of the specific objectives referred above (which probably happens in some firms' categories analysed in this paper). However, the reverse is much more difficult to apply - i.e., it is hardly the case that public support is contributing positively to its stated objectives while having no impact, or even a negative impact, in terms of firms' survival and job creation. Accordingly, the results of this study should be seen not as sufficient, but as necessary to conclude that the public support policies to firms' investment, implemented under the POE / PRIME, positively reached the overall objectives, defined in program documents and regulations.

\section{2) Incentives are particularly effective in the case of firms that are typically more fragile.}

This is particularly true for new firms and/or firms with low financial autonomy.

It is well known that liquidity and funding restrictions faced by firms vary considerably among them, regardless of their characteristics. On the one hand, companies differ in their ability to 


\section{Counterfactual impact evaluation of EU funded enterprise support in Portugal}

negotiate with customers and suppliers (particularly given their size and turnover), affecting their liquidity needs. On the other hand, firms vary in the conditions they face to access external finance. Typically, larger companies with greater financial autonomy and/or whose business involves less risk (commercial, technological, natural, political, etc.) are able to obtain better financing terms from banks and other lenders, regardless of the expected return of the firm's investment project.

In that sense, the results of this study are not surprising, and confirm the intuition that public support makes the most difference when it is directed to firms who need it most, thus contributing to correct a major market failure.

Even if not surprising, the results raise an important issue for the design of public policies. Usually, enterprise support schemes establish minimum levels of firms' financial autonomy as an eligibility criterion. Basically, this practice is determined by the need to reduce the risks of failure due insufficiency of firms' assets. However, our findings suggest that the impact of support is clearly higher in the case of firms whose level of financial autonomy is reduced. This result points to the need to balance between the risk assumed by the policies and their effective impact on economic activity.

\section{3) Regarding firm size, the support has positive and greater impacts in the case of large} firms, and the average cost (for public funds) per job created is smaller than the one estimated for comparable firms of other size classes.

The estimated impact of support on net employment growth in large firms is higher than in the case of firms that are similar in every respect, except in size. Again, this result is not surprising, since the absolute variation of jobs resulting from the firms' investment tends to be substantially higher in the case of larger firms, whose investment projects are typically bigger.

The less obvious aspect of the results concerns the average cost (in terms of the amount of public incentive) for each additional job created. In fact, some studies of a similar nature that have been made in other EU Member States (see Mouqué, 2012) conclude that although job creation arising from public support is higher in the case of large firms, its average cost per job created tends to be higher, i.e., the amount of support, in general, is proportionally higher than the number of jobs created (by comparison with SMEs).

Still, it should be noted that in Portugal and for the whole set of incentives, the public co-financing rates are substantially lower for large firms than to SMEs. Therefore, in light of this practice, it is expected that the average cost for public funds tends to be lower for nonSMEs, for identical levels of total investment per job created. In other words, the differences in incentive fees between SMEs and non-SMEs may explain the fact that the results of this study 
contrast with the findings of similar studies conducted in other countries with regard to the average cost per job created by large firms.

4) Our results suggest that public support is more effective in terms of job creation for firms operating in supra-regional markets, regardless of firm size or industry. For firms operating in infra-regional markets, the impact of the public support is more relevant in terms of survival.

In this study, the firms were divided in two main groups: those that operate primarily in regional or infra-regional markets, and those whose business scope transcends regional borders. This classification can be seen as a refinement of the usual distinction between tradable and nontradable sectors. For the present purposes, we assume that micro-firms always target specific infra-regional market segments, while medium and large firms operate in supra-regional markets, regardless of industry.

The results suggest that the impact of policies on employment is greater for firms that operate in markets of wider geographical scope, regardless of size or industry. These results suggest that the option that has been taken in public policy in Portugal, favouring firms that operate in markets that are more exposed to international competition, is appropriate to the creation of employment at the firm level ${ }^{15}$.

In the case of firms mainly oriented to regional or infra-regional markets, the support tends to produce greater impacts in terms of survival than of job creation, when compared to firms operating in supra-regional markets.

\section{5) The average cost per additional job created as a result of incentives is relatively modest.}

According to the estimates presented above, the incentive associated to each additional job created as a result of public support corresponds to 55000 euros. Note that the job growth is measured in a time period of three years. Assuming that the job was created in the firm at the time of realization of the investment project, this means that the cost of each additional employment generated is about 18000 euros per year. However, it should be emphasized that we are considering as support the amount paid to the beneficiary - and not necessarily the total cost of public support. In fact, part of the incentives assumes a refundable nature (it is a soft loan, rather than a grant), so the estimated average cost constitutes an upper limit of public effort per job created.

\footnotetext{
${ }^{15}$ Note that we are not assessing the overall impact of support on job creation in the economy. Such assessment requires the use of methods that significantly differ from those used in the present work.
} 


\section{Counterfactual impact evaluation of EU funded enterprise support in Portugal}

Moreover, the net creation of jobs in supported firms is not a primary objective of these policies - which are typically designed to promote productivity, innovation and firms' internationalization, as well as the upgrading of the specialization profile of the Portuguese economy. Assuming that part of the public effort reflects the pursuit of these goals, the positive impact of incentives on job creation should be seen, to some extent, as an extra benefit (rather than the core) of these policies.

As was made clear in the introduction, the analysis carried out in this paper is limited by the available information. In particular, we would have liked to extend the control variables beyond the ones we used in the paper. For example, we could not take into account the investment cycle of the firms. This means that within our control group there may be cases of firms that have made relevant investments in the years that immediately precede the period under review, the impacts of which may have already been felt. Given this possibility it would be advisable to control for the previous investments, in order to assure the comparability between treated and non-treated firms. To some extent, the selection bias that may result from not controlling for the investment cycle is reduced when we restrict the period under analysis to 2005-2006 (see section 7.1), since in this case we are excluding from the control group all the firms that received support in the period 2000-2004. Still, many treated firms here considered as substantively indistinguishable from non-treated ones may not be so.

Our future research will seek to enrich the analysis conducted in this paper by merging our dataset with additional data, which should allow us to:

- deepen the characterization of firms, in order to further reduce selection effects;

- analyse the impact of incentives in relation to relevant policy objectives that were not considered here (e.g., productivity, innovation and internationalization);

- consider schemes of firms incentives under the NSRF, and

- analyse data covering the time period after the outbreak of the international crisis of 2008/2009. 


\section{Counterfactual impact evaluation of EU funded enterprise support in Portugal}

\section{REFERENCES}

BERNARD, A. B., \& Jones, C. I. (1996). "Productivity across industries and countries: time series theory and evidence". The review of economics and statistics, 135-146.

BOXALL, P., \& Macky, K. (2009). Research and theory on high-performance work systems: progressing the high-involvement stream. Human Resource Management Journal, 19(1), 3-23. doi:10.1111/j.1748-8583.2008.00082.x

DOSI, G. (1982). "Technological paradigms and technological trajectories: a suggested interpretation of the determinants and directions of technical change". Research policy, 11(3), 147-162.

EC (2015), Guidance Document on Evaluation Plans, Programming Period of 2014-2020 (available at:

http://ec.europa.eu/regional_policy/sources/docoffic/2014/working/evaluation_plan_guidance e n.pdf).

GEROSKI, P. A. (1995). "What do we know about entry?". International Journal of Industrial Organization, 13(4), 421-440.

MOUQUÉ, D. (2012). "What are counterfactual impact evaluations teaching us about enterprise and innovation support?". Regional Focus 02/2012.

IACUS, S.; King, G.; Porro, G. (2012). "Causal Inference without Balance Checking: Coarsened Exact Matching”. Political Analysis 20 (1), 1-24. 